\title{
Exploring the potential of remote plasma sputtering for the production of L10 ordered FePt thin films
}

DOI:

10.1088/1361-6463/aa761a

\section{Document Version}

Accepted author manuscript

Link to publication record in Manchester Research Explorer

\section{Citation for published version (APA):}

Zygridou, S., Barton, C., Nutter, P., \& Thomson, T. (2017). Exploring the potential of remote plasma sputtering for the production of L1 ordered FePt thin films. Journal of Physics D: Applied Physics, 50(27).

https://doi.org/10.1088/1361-6463/aa761a

\section{Published in:}

Journal of Physics D: Applied Physics

\section{Citing this paper}

Please note that where the full-text provided on Manchester Research Explorer is the Author Accepted Manuscript or Proof version this may differ from the final Published version. If citing, it is advised that you check and use the publisher's definitive version.

\section{General rights}

Copyright and moral rights for the publications made accessible in the Research Explorer are retained by the authors and/or other copyright owners and it is a condition of accessing publications that users recognise and abide by the legal requirements associated with these rights.

\section{Takedown policy}

If you believe that this document breaches copyright please refer to the University of Manchester's Takedown Procedures [http://man.ac.uk/04Y6Bo] or contact uml.scholarlycommunications@manchester.ac.uk providing relevant details, so we can investigate your claim.

\section{OPEN ACCESS}




\title{
Exploring the potential of remote plasma sputtering for the production of $\mathrm{L1}_{0}$ ordered FePt thin films
}

\author{
S. Zygridou ${ }^{1}$, C. W. Barton ${ }^{1}$, P. W. Nutter ${ }^{1}$ and T. Thomson ${ }^{1}$ \\ ${ }^{1}$ Nano Engineering \& Storage Technologies Research Group, School of Computer Science, The \\ University of Manchester, Oxford Road, Manchester, M13 9PL, UK
}

\begin{abstract}
Lowering the temperature at which the desirable $\mathrm{L}_{0}$ phase forms in $\mathrm{FePt}$ thin films is a key requirement in the development of next generation high-density data storage media and spintronic devices. Remote plasma sputtering offers a higher degree of control over the sputtering parameters, allowing the properties of films to be tailored, and potentially can affect the ordering kinetics of the $\mathrm{L} 1_{0}$ phase of FePt. Here, we report a comprehensive study of FePt thin films deposited under a range of temperatures and sputtering conditions. X-ray diffraction and magnetometry investigations show that whilst FePt thin films ordered in the $\mathrm{L}_{0}$ phase with high perpendicular anisotropy can be produced using this technique, there is no significant reduction in the required ordering temperature compared with films produced using conventional DC sputtering. Optimally ordered $\mathrm{L} 1_{0} \mathrm{FePt}$ films were fabricated when the film was deposited at a substrate temperature of $200^{\circ} \mathrm{C}$, followed by post annealing at $750^{\circ} \mathrm{C}$.
\end{abstract}




\section{Introduction}

The increase in the areal density of hard disk drives has slowed considerably over the last few years as conventional perpendicular recording matures, with values of approximately $1 \mathrm{Tbit} / \mathrm{in}^{2}$ currently available in commercial products [1]. A number of approaches have been deployed to enhance the areal density including shingled magnetic recording [2] and the use of helium gas to decrease the fly height of the $\mathrm{read} / \mathrm{write}$ head and reduce energy consumption [3]. However, in order to increase areal density significantly a new paradigm is needed. Heat assisted magnetic recording (HAMR) has emerged as the key technology in the quest for higher areal densities [4], as it allows a balance between the thermal stability of the recorded data (dictated by the product of the magnetic anisotropy and grain volume, $\mathrm{KuV}$ ), the writability of the media (given by the field available from a recording head), and the signal to noise ratio (SNR) of the recovered data (number of grains in a bit); also referred to as the trilemma of magnetic recording [5]. In order to address the trilemma, a recording medium of very high anisotropy is required, which allows the grain size to be reduced whilst still maintaining high thermal stability. However, it is impossible to write data to very high anisotropy media using the limited write field produced by the conventional magnetic write head. HAMR overcomes the issue of writability by heating the recording medium to locally reduce the anisotropy, enabling data to be recorded using the magnetic fields produced by the conventional write head. However, a good SNR on readout is also required, which requires the medium to have a small $(<10 \mathrm{~nm})$ and well-controlled grain size distribution to enable narrow magnetic transitions to be recorded. $\mathrm{L} 1_{0}$ ordered FePt thin films offer the most promising route to achieving magnetic storage media that satisfies these requirements due to the high perpendicular magnetic anisotropy of $7 \times 10^{7} \mathrm{erg} / \mathrm{cm}^{3}$ in the bulk, the ability to form grains and nanoparticles of a few nanometers diameter, and a Curie temperature of $\mathrm{T}_{\mathrm{c}} \approx 750 \mathrm{~K}$ in excess of room temperature [6]. FePt is a binary alloy that can be fabricated with different structural phases and hence exhibit different magnetic properties. In the $\mathrm{L}_{0}$ phase the crystal structure of FePt consists of alternate monoatomic layers of $\mathrm{Fe}$ and $\mathrm{Pt}$ along the (001) direction, providing the high magnetic perpendicular anisotropy that makes these materials ideal candidates for HAMR $[6,7]$. However, creating $\mathrm{L} 1_{0}$ ordered $\mathrm{FePt}$ thin films with desirable properties remains a significant challenge, since high deposition temperatures (typically in excess of $500^{\circ} \mathrm{C}$ ) are required to form the required level of ordering $[8,9,10]$, making such media difficult to fabricate using the industrial processes developed for producing current commercial magnetic hard disks [11]. In addition, precise control of the (001) texture and microstructure of FePt thin films is required [6].

Remote plasma sputtering utilizes a novel plasma sputtering technology - High Target Utilisation Sputtering (HiTUS) - developed by Thwaites $[12,13]$. The technique utilitises a high intensity plasma that, unlike conventional DC magnetron sputtering systems, is generated remotely away from the target. 
Figure 1 shows the main features of remote plasma sputtering, where the remotely generated plasma is brought into the main deposition chamber and is guided to the target by a pair of electromagnets. As the plasma generation is decoupled from the sputtering process and the RF power, the energy of the ions impacting the target can be controlled independently [13]. Due to the ability to tune the target DC bias voltage $(0-1000 \mathrm{~V})$ independently of the plasma generation, the acceleration energy of the $\mathrm{Ar}^{+}$ions can be more precisely controlled. In addition, by generating the plasma remotely from the target then more uniform target erosion is achieved, which provides economic advantages when using expensive raw materials such as Pt. Control of the grain size and coercivity of CoFe films $[13,14]$ and of the perpendicular magnetic anisotropy in $\mathrm{Co} / \mathrm{Pd}$ multilayer thin films [15] have been reported using this deposition technique.

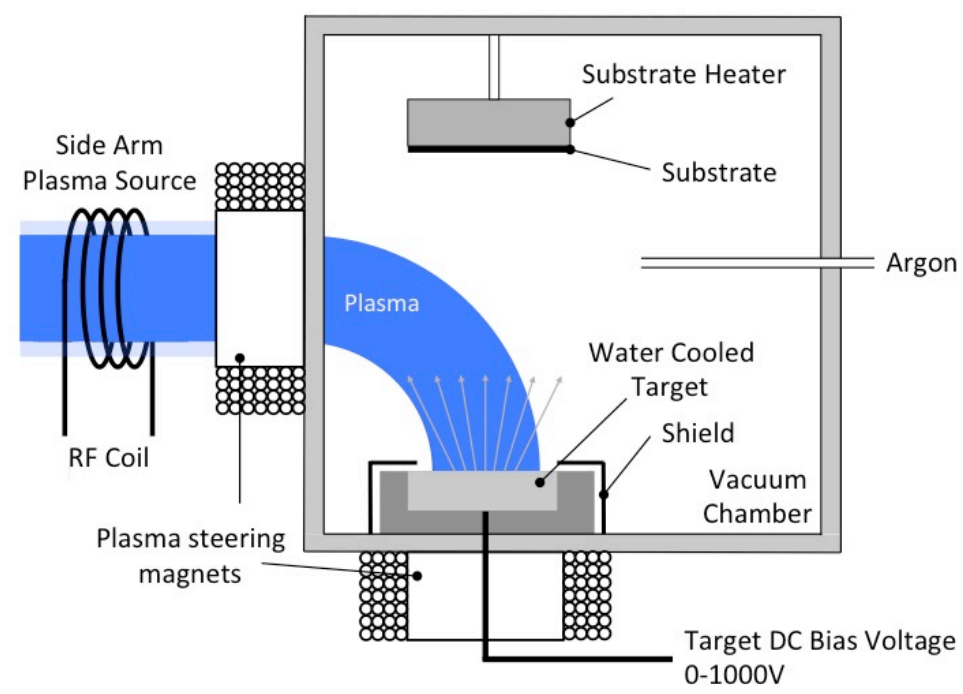

Figure 1. Schematic of the HiTUS remote plasma sputtering approach. The plasma is generated remotely away from the target and is decoupled from the sputtering process. The plasma is brought to incidence on the target by a pair of steering magnets.

Significant literature exists where various methods to control and potentially lower the ordering temperature required to induce the $\mathrm{L} 1_{0}$ ordered phase in $\mathrm{FePt}$ have been proposed. Examples include changing the Fe concentration [16, 17], adding doping elements such as $\mathrm{Cu}[18,19], \mathrm{Au}, \mathrm{Ag}[20]$ and $\mathrm{Zr}$ [21], strain-induced transformation [22], and the monatomic layer deposition of Fe and Pt [23]. However, the application of remote plasma sputtering for the fabrication of these films remains largely unexplored. The only significant work on remote plasma sputtering of FePt was reported by Tran \& Wright [24] who observed the formation of Fe and Pt silicides when annealing FePt thin films deposited on Si substrates at high temperatures. Here we explore the potential of remote plasma sputtering to create $\mathrm{L} 1_{0}$ ordered $\mathrm{FePt}$ 
thin films with modified properties. In particular, we focus on investigating whether depositing FePt at elevated substrate temperatures can reduce the post annealing temperature required to develop the $\mathrm{L} 1_{0}$ phase in FePt thin films deposited using this technique.

\section{Experiment}

FePt thin films were deposited by remote plasma sputtering using a PlasmaQuest/Lesker system on to single-crystal $\mathrm{MgO}(001)$ substrates from a $\mathrm{Fe}_{50} \mathrm{Pt}_{50}$ at\% (equatomic) target. The films were sputtered at a RF power of $1 \mathrm{~kW}$ and at a range of target DC bias voltages $(200 \mathrm{~V}, 600 \mathrm{~V}$, and $1000 \mathrm{~V})$ and substrate deposition temperatures (room temperature, $200^{\circ} \mathrm{C}, 300^{\circ} \mathrm{C}$ ), where the maximum substrate temperature is limited by the capabilities of the substrate heater used. In all cases the $\mathrm{MgO}$ substrates were baked at $300^{\circ} \mathrm{C}$ in-situ for an hour prior to the deposition of the thin film. The vacuum chamber base pressure was better than $8 \times 10^{-9} \mathrm{mbar}$ for the deposition at room temperature.

Post annealing of the deposited films was performed using two approaches. In the first approach, the asdeposited films were placed in an Anton-Parr high-temperature oven (under a vacuum of $\sim 10^{-4} \mathrm{mbar}$ ) mounted in a Phillips X'pert Pro diffractometer, which allows X-ray diffraction (XRD) measurements to be performed in-situ as the annealing temperature is varied. The fcc to $\mathrm{L} 1_{0}$ transition is not expected to depend strongly on annealing time, in the tens of minutes range, as shown by time-temperaturetransformation (TTT) diagrams [25], therefore, an annealing time of 30 minutes was chosen, with a further 45 minutes for the in-situ XRD measurement at each temperature. The XRD measurements used $\mathrm{Cu}-\mathrm{K}_{\alpha}$ radiation of wavelength $\lambda=1.5418 \AA$, and a PANalytical X'Celerator detector. $\theta-2 \theta$ scans provided data on the crystallographic structure of the FePt thin films in the perpendicular (out of plane) direction. In the second approach, fresh samples were annealed ex-situ in a conventional tube furnace for 1 hour in an $\mathrm{Ar} / 10 \% \mathrm{H}_{2}$ reducing atmosphere in order to minimize oxidation, after which XRD measurements were performed using the Philips X'pert Pro diffractometer. In order to investigate the (001) texture of the fabricated FePt thin films the lattice parameters were obtained by analysing the peaks in the XRD spectra [26]. The order parameter is often used as a measure of the level of ordering in a film, which is determined by fitting to the peaks in the XRD data. However, in our XRD data the background contribution along with the available instrument configuration introduces significant uncertainty into the calculated values. Therefore, we investigate the level of $\mathrm{L}_{0}$ ordering through the intensity of the fcc FePt (200) and $\mathrm{L} 1_{0} \mathrm{FePt}(001)$ and (002) peaks in the XRD data. 
The magnetic properties of the thin films were measured at room temperature using a MicroSense Model 10 vector VSM, which allows a maximum magnetic field of $2 \mathrm{~T}$ to be applied in different geometries. This enables measurements of in-plane and perpendicular (out of plane) hysteresis loops to be made from which values of the saturation magnetization (Ms), coercivity $(\mathrm{Hc})$ and anisotropy can be obtained. All VSM measurements were carried out at room temperature. The anisotropy field, $\mathrm{H}_{\mathrm{k}}$, was obtained from the field required to saturate the film in the hard axis direction. In the case where the available applied field of $2 \mathrm{~T}$ was insufficient to saturate the sample, $\mathrm{H}_{\mathrm{k}}$ was estimated by extrapolation.

\section{Results \& Discussion}

\subsection{In-situ studies of FePt ordering}

Initial studies focused on determining the evolution of the $\mathrm{L} 1_{0}$ ordering as $\mathrm{FePt}$ films deposited using remote plasma sputtering were annealed at increasing temperatures. In this study, a 20nm FePt film was deposited on to an $\mathrm{MgO}(001)$ substrate at a target DC bias voltage of $200 \mathrm{~V}$, followed by a $5 \mathrm{~nm} \mathrm{Pt}$ capping layer. The substrate temperature was held at $200{ }^{\circ} \mathrm{C}$ throughout the deposition.

Figure 2 (a) shows the in-plane and perpendicular (out-of plane) hysteresis loops for the as-deposited film (sample PQ441a) measured by VSM. The hysteresis data shows that the easy axis for the as-deposited field lies in-plane with a measured saturation magnetization of $M_{s}=1180 \mathrm{emu} / \mathrm{cm}^{3}$, which matches the expected value given in literature [7]. The anisotropy field, $H_{k}$, was measured as the field at which the perpendicular loop (hard axis) saturates, and is approximately $14 \mathrm{kOe}$, which demonstrates that, as expected, shape anisotropy dominates.

The annealing temperature at which the onset of $\mathrm{L} 1_{0}$ ordering occurs was determined from the peaks in the XRD data, where the annealing of the samples was performed using the Anton-Paar high-temperature oven. Figure 3 shows the change in the XRD data as the annealing temperature is increased in steps from $300^{\circ} \mathrm{C}$ to $800^{\circ} \mathrm{C}$ (sample PQ441a). The presence of $\mathrm{L} 1_{0}$ ordering is signified by the presence of a FePt (001) peak, and the presence of perpendicular texture by the presence of a FePt (002) peak in the XRD data. The as-deposited film (bottom line) does not exhibit a (001) diffraction peak, which indicates that there is no $\mathrm{L} 1_{0}$ ordering present in the as-deposited film. The evolution of (001) and (002) peaks is observed as the annealing temperature is increased, with the (001) peak becoming more clearly defined for annealing temperatures in excess of $450^{\circ} \mathrm{C}$. The inset of Figure 3 shows the XRD data for the (200) and (002) peaks for annealing temperatures of $650^{\circ} \mathrm{C}, 700^{\circ} \mathrm{C}$ and $750^{\circ} \mathrm{C}$ where a large change in relative intensity occurs. The (002) peak first appears for an annealing temperature of $700^{\circ} \mathrm{C}$, where the (200) and 
(002) peaks are combined, which along with the presence of the (001) peak indicates that there is perpendicular ordering with some disorder still present [27]. As the annealing temperature is increased an increase in the intensity of the (001) and (002) peaks is observed along with a reduction in the intensity of (200) peak, with the (001) and (002) peaks becoming sharper and more pronounced for annealing temperatures of $750^{\circ} \mathrm{C}$ and $800^{\circ} \mathrm{C}$. As the amplitude of the (001) and (002) peaks is similar at these annealing temperatures we can conclude that a temperature of $750^{\circ} \mathrm{C}$ is sufficient to order the film.
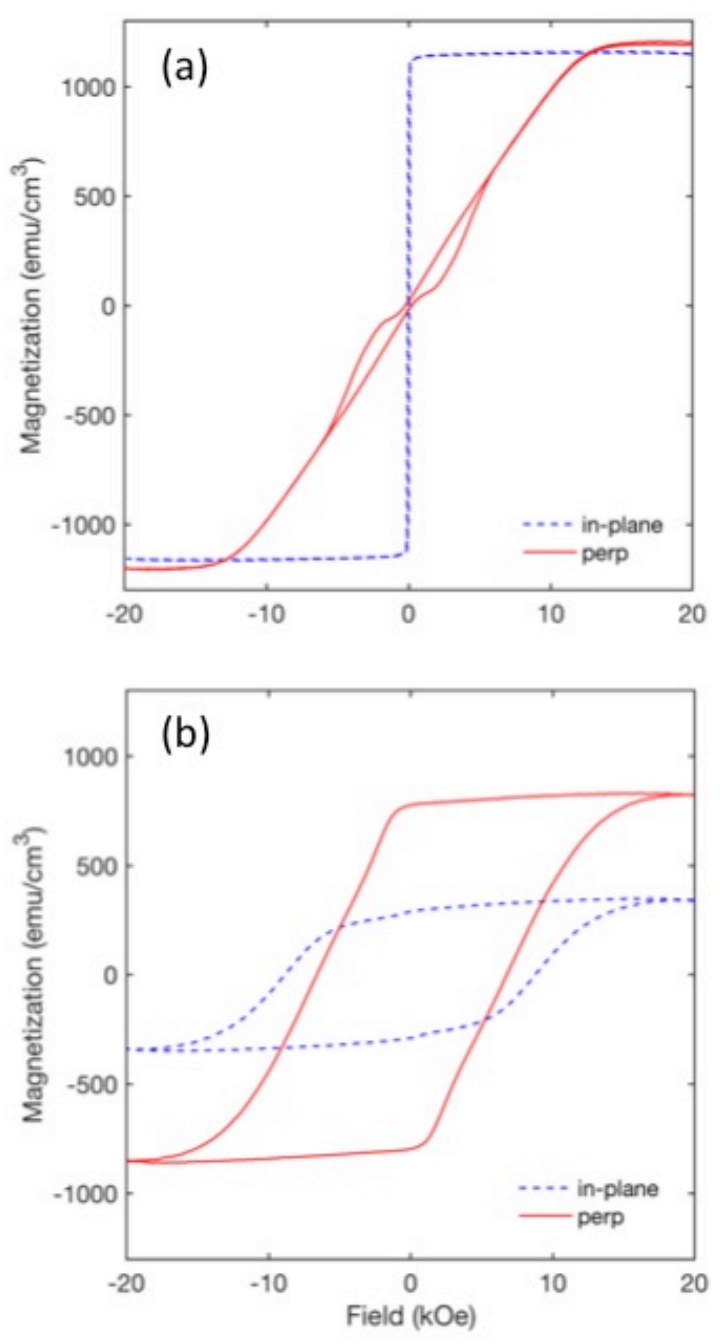

Figure 2 In-plane (dotted) and perpendicular (solid) hysteresis loops for a FePt thin film measured using VSM (sample PQ441a), (a) as deposited, and (b) after annealing at $800^{\circ} \mathrm{C}$. 


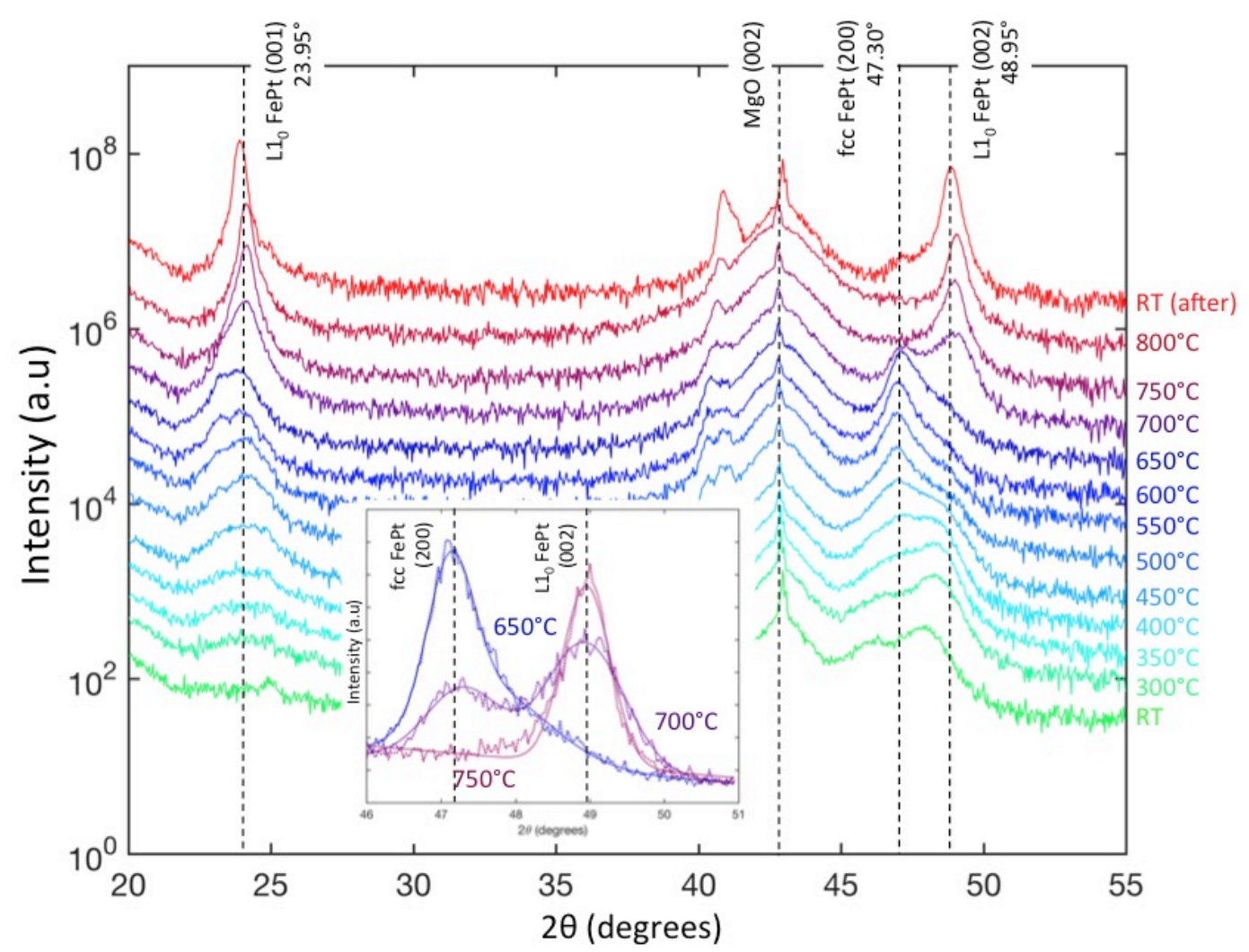

Figure 3. Waterfall graph of the perpendicular (out of plane) XRD data for the 20nm thick FePt film with a $5 \mathrm{~nm}$ Pt capping layer (PQ441a) deposited using a target DC bias voltage of $200 \mathrm{~V}$ and at a substrate temperature of $200^{\circ} \mathrm{C}$. The XRD data at room temperature and a range of annealing temperatures from $300{ }^{\circ} \mathrm{C}$ to $800{ }^{\circ} \mathrm{C}$, is shown. The inset shows fitted curves for the (200) and (002) peaks at annealing temperatures of $650^{\circ} \mathrm{C}, 700^{\circ} \mathrm{C}$ and $750^{\circ} \mathrm{C}$ where evidence of $\mathrm{L} 1_{0}$ ordering first appears.

Figure 2 (b) shows in-plane and perpendicular hysteresis loops measured at room temperature by VSM after annealing at $800^{\circ} \mathrm{C}$. The hysteresis data shows that there is still an in-plane component, which indicates that not all the film is ordered out of the plane. This is evidenced by the appearance of a small fcc FePt (200) component in the XRD data (see RT (after) in Figure 3) and a shifting of the angle of the (002) peak to lower angles, which is an indication of bipolar ordering where there are fcc disordered regions in the homogeneously ordered film [28]. A reduction in $\mathrm{M}_{\mathrm{s}}$ from 1180 to $865 \mathrm{emu} / \mathrm{cm}^{3}$ is observed compared with the as-deposited sample. Reductions in $\mathrm{M}_{\mathrm{s}}$ are frequently observed in ordered FePt thin films and are most likely due to oxidation from the substrate or breakdown of the capping layer due to the relatively poor vacuum in the XRD temperature stage. Diffusion of Pt from the capping layer, resulting in a change in composition of the film, may also play a role in the reduction of $\mathrm{M}_{\mathrm{s}}$. 
Consequently, to investigate these films further we performed subsequent annealing studies using a traditional tube furnace in a controlled $\mathrm{Ar} / \mathrm{H}_{2}$ atmosphere in order to minimize any degradation resulting from oxidation/contamination of the film.

\subsection{Effect of substrate temperature and target DC bias voltage-anneal at $700^{\circ} \mathrm{C}$}

Using the information gained from the in-situ XRD study described in section 3.1, we explored how the substrate temperature and target DC bias voltage affect the ordering in FePt thin films when the films are annealed at $700{ }^{\circ} \mathrm{C}$. A matrix of $10 \mathrm{~nm}$ thick FePt thin films with no capping layer were sputtered at different substrate temperatures (room temperature (RT), $200^{\circ} \mathrm{C}$, and $300{ }^{\circ} \mathrm{C}$ ), and different target DC bias voltages $(200 \mathrm{~V}, 600 \mathrm{~V}$ and $1000 \mathrm{~V})$ as listed in Table 1. Figure 4 (a) shows a representative loop for the film deposited at $200{ }^{\circ} \mathrm{C} / 200 \mathrm{~V}$ (PQ468b); all the as-deposited films exhibit a similar in-plane anisotropy.

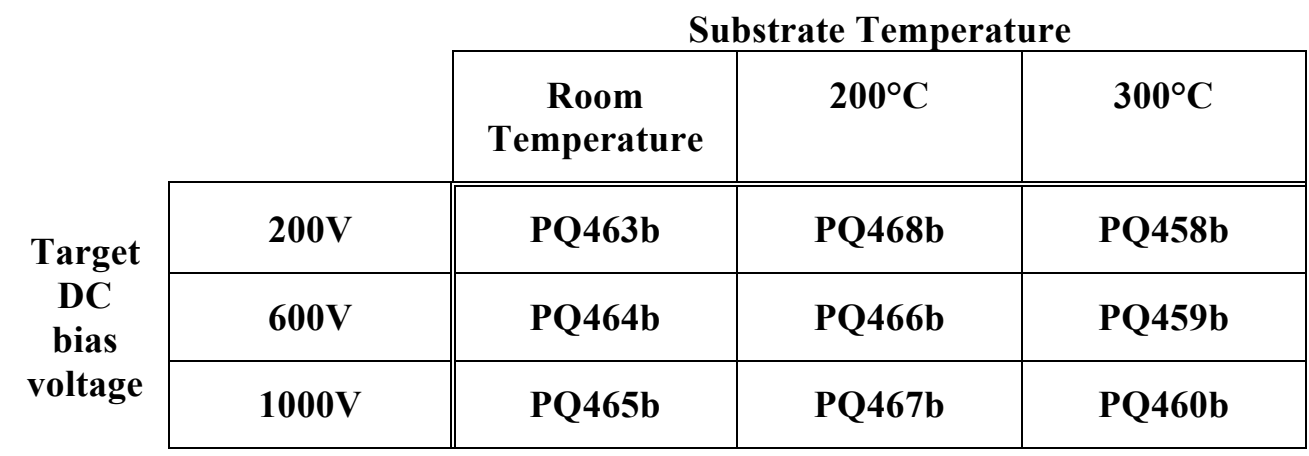

Table 1. Matrix of FePt samples deposited using a range of target DC bias voltages and substrate temperatures.

Calculated uniaxial anisotropy, $\mathrm{K}_{\mathrm{u}}$, values $[14,29,30]$ for the as-deposited films are plotted in Figure 4 (b) as a function of substrate temperature and target DC bias voltage. The films exhibit a low anisotropy phase, dominated by shape anisotropy, which reduces as the target DC bias voltage is increased, and is largely independent of the substrate temperature. XRD data for the as-deposited films (not presented) show a disordered fcc FePt (200) diffraction peak and no FePt (001) and (002) peaks demonstrating the absence of any ordering in the films. The XRD data were analyzed by fitting a Gaussian function to the (200) peaks and the c-lattice parameter was calculated [31] as shown in Figure 4 (c). The shaded region represents the range of published values for the c-lattice parameter for disordered FePt thin films. The clattice parameter depends on film thickness and varies from $3.85 \AA$ for the bulk to $3.8 \AA$ for thin films [10, $32,33]$. In all cases the c-lattice parameter is less when higher substrate temperatures are used, suggesting that depositing at a higher temperatures supports ordering in the film. The smaller c-lattice constant for 
the sample deposited at a target DC bias voltage of $200 \mathrm{~V}$ suggests a greater level of ordering in the film. The reduction of the c-lattice parameter correlates with a higher anisotropy in these films, Figure 4 (b), which gives further evidence for some level of ordering in the film. However, shape anisotropy still dominates resulting in a net in-plane anisotropy. At higher target DC bias voltages the measured c-lattice constant is within the range of values associated with a disordered FePt phase, which agrees with the lower anisotropy values calculated for these samples, Figure 4 (b).
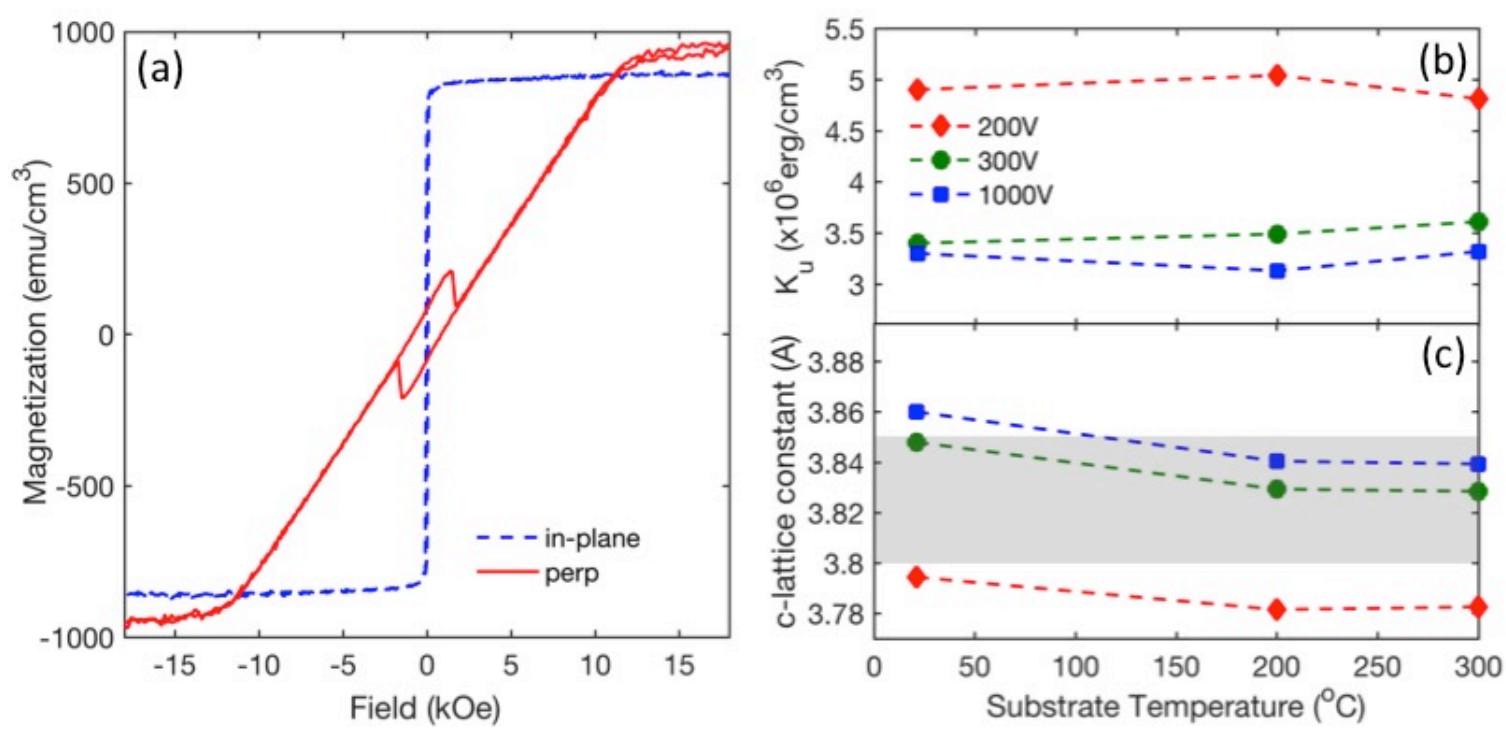

Figure 4. Data for the as-posited thin films deposited using a range of target DC bias voltages for a range of substrate temperatures. a) VSM measurement for the as-deposited FePt thin film for a target DC bias voltage of $200 \mathrm{~V}$ and at a substrate temperature of $200^{\circ} \mathrm{C}$ (PQ468b). b) calculated uniaxial anisotropy, $\mathrm{K}_{\mathrm{u}}$, and c) measured c-lattice constant of the as-deposited films as a function of target DC bias voltage and substrate temperature during deposition. The shaded region in c) represents the range of c-lattice parameters for disordered FePt for bulk and thin film [10, 32, 33].

The XRD results reported in section 3.1 demonstrated that for FePt films deposited at a substrate temperature of $200^{\circ} \mathrm{C}$ there was evidence of $\mathrm{L}_{0}$ ordering when these samples were post-annealed at temperatures in excess of $700^{\circ} \mathrm{C}$. We take this temperature as a starting point in order to investigate the properties of this matrix of films, which have been annealed in the tube furnace for 1 hour. The matrix of films is then fully characterized by XRD and magnetometry. 
Figure 5 shows the perpendicular hysteresis loops for the samples after annealing at $700^{\circ} \mathrm{C}$. The hysteresis loops exhibit strong perpendicular hysteresis indicating the presence of the perpendicular $\mathrm{L} 1_{0}$ ordered phase after annealing. However, there is a small magnetization step ("kink") around remanence that is an indicator of the presence of a softer magnetic phase. There are a number of potential causes of these unwanted phases including contamination, isolated, disordered, low anisotropy regions leading to superparamagnetic behavior [34], or low anisotropy regions where the demagnetization field causes reversal nucleation [35].

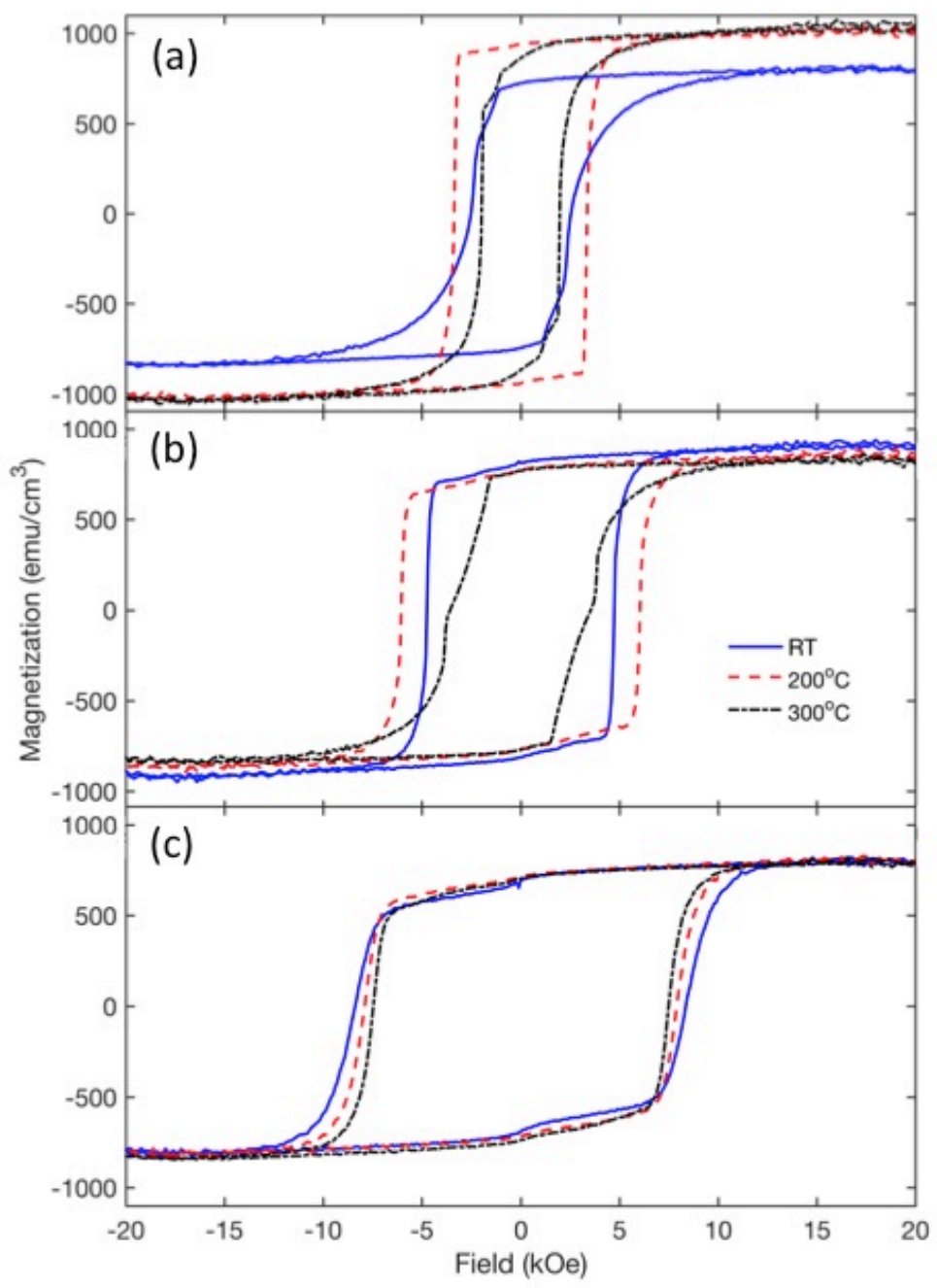

Figure 5. Perpendicular VSM measurements of the FePt thin films after annealing at $700^{\circ} \mathrm{C}$ for target DC bias voltages of (a) $200 \mathrm{~V}$, (b) $600 \mathrm{~V}$, and (c) $1000 \mathrm{~V}$, as a function of deposition temperature.

Figure 6 shows the effect of the substrate temperature and target DC bias voltage on the coercivity, $\mathrm{H}_{c}$, and anisotropy, $\mathrm{K}_{\mathrm{u}}$, for all the films in the matrix at after annealing. Figure 6 (a) shows that the samples 
annealed at $700^{\circ} \mathrm{C}$ exhibit an increase in coercivity as the DC target bias voltage is increased. In the case of anisotropy, Figure 6 (b), the annealing of the samples has resulted in the formation of a high perpendicular anisotropy phase in contrast to the shape dominated in-plane anisotropy of the as-deposited film (Figure 4). The highest anisotropy being observed for the film deposited at a target DC bias voltage of $200 \mathrm{~V}$ and at higher substrate temperatures. The anisotropy field, $\mathrm{H}_{\mathrm{k}}$, was estimated by linear extrapolation of the hard axis (in-plane) loop and was found to be greater than $20 \mathrm{kOe}$ for all the thin films produced.
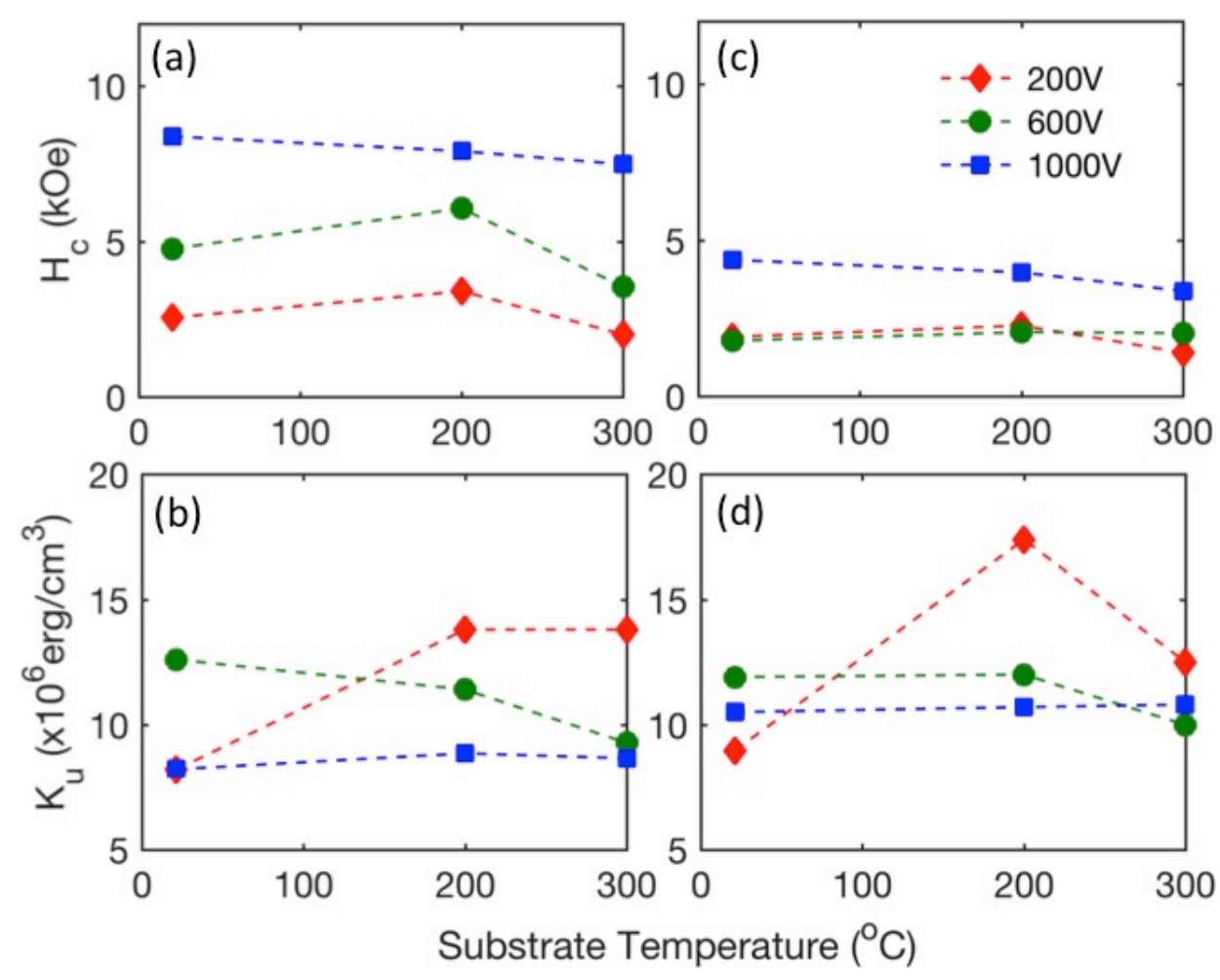

Figure 6. Coercivity, $\mathrm{H}_{\mathrm{c}}$, and calculated uniaxial anisotropy, $\mathrm{K}_{\mathrm{u}}$, of the FePt thin films after annealing at $700^{\circ} \mathrm{C}(\mathrm{a})$ and $(\mathrm{b})$, and $750^{\circ} \mathrm{C}(\mathrm{c})$ and (d), as a function of target DC bias voltage and substrate temperature.

Figure 7 shows the measured XRD data for the films after annealing at $700^{\circ} \mathrm{C}$. The presence of a fcc FePt (200) peak in the data is indicative of more disordered grains in the film, as discussed in section 3.1. In the case of the film deposited at a target DC bias voltage of 200V, Figure 7(a), the (200) peak is present for the samples deposited at room temperature and $300^{\circ} \mathrm{C}$. However, for the sample deposited at $200^{\circ} \mathrm{C}$ the intensity of the (200) peak is significantly reduced indicating that the level of ordering in this sample 
is much improved. For the samples deposited at a target DC bias voltage of $1000 \mathrm{~V}$ the presence of the (200) peak leads to combined broad (200) and (002) peaks indicating an increased level of disorder in the film; this could account for the high coercivity in these films, possibly due to domain wall pinning at boundaries between disordered (fcc) and ordered $\left(\mathrm{L1}_{0}\right)$ phases [10].

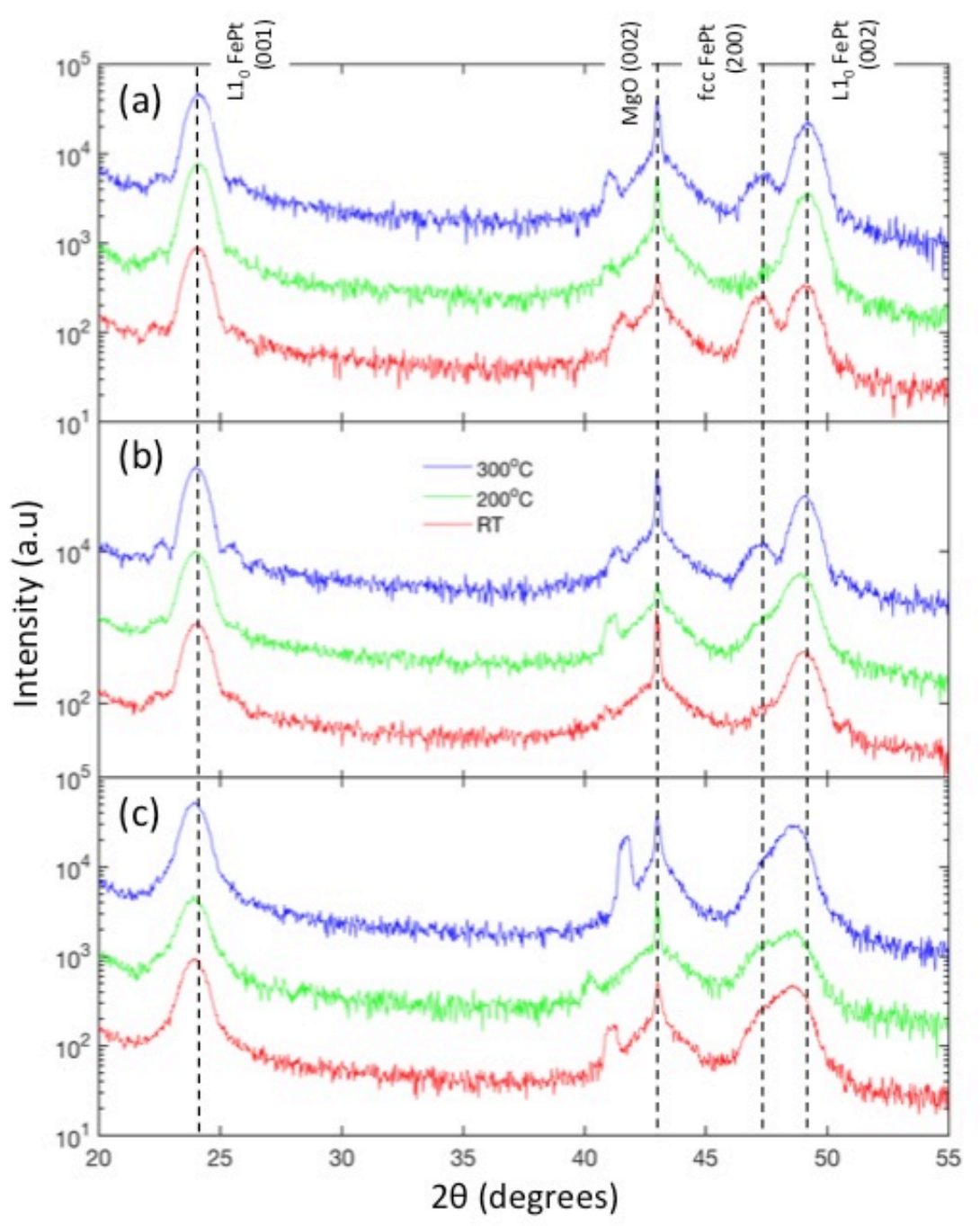

Figure 7. Perpendicular (out of plane) XRD data of the FePt thin films after annealing at $700^{\circ} \mathrm{C}$, deposited using a target DC bias voltage of (a) 200V, (b) $600 \mathrm{~V}$, and (c) $1000 \mathrm{~V}$, as a function of deposition temperature. The $2 \theta$ angles of the $\mathrm{MgO}(002)$, fcc FePt(200), $\mathrm{L}_{0} \mathrm{FePt}(001)$ and (002) peaks are shown.

The c-lattice constant for the films annealed at $700^{\circ} \mathrm{C}$ was calculated and is plotted in Figure 8 (a). The clattice constant for bulk $\mathrm{L} 1_{0}$ ordered FePt is $\mathrm{c}=3.713 \AA[19,20]$, which is highlighted as "ideal $\mathrm{L} 1_{0} \mathrm{FePt}$ " 
in Figure 8, whereas in the thin film case $\mathrm{c}=3.74 \AA$ (4.2 $-8.4 \mathrm{~nm}$ thick films [10]). It can be seen that in all cases the c-lattice constant is close to that expected for the bulk ordered $\mathrm{L} 1_{0} \mathrm{FePt}$, in particular for the case of target DC bias voltages of $200 \mathrm{~V}$ and $600 \mathrm{~V}$, which is a further indication that we have better ordering in these films. However, the c-lattice constant appears to exhibit little variation with substrate deposition temperature.

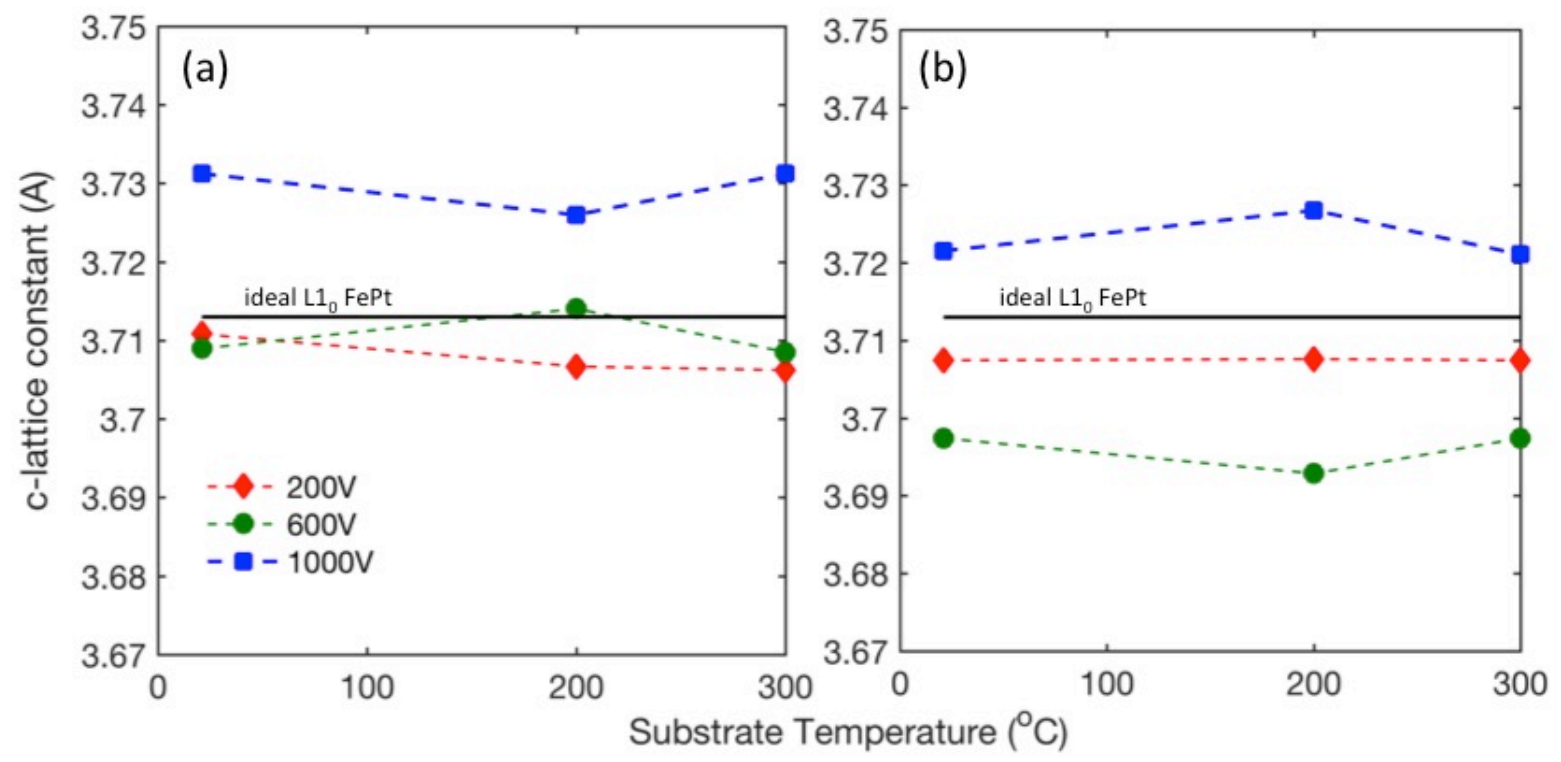

Figure 8. c-lattice constant of the FePt thin films after annealing at (a) $700^{\circ} \mathrm{C}$ and (b) $750^{\circ} \mathrm{C}$ as a function of target DC bias voltage and substrate temperature. The solid line indicates the c-lattice constant for ideal bulk $\mathrm{L} 1_{0}$ ordered FePt $[19,20]$.

\subsection{Effect of substrate temperature and target DC bias voltage-anneal at $750^{\circ} \mathrm{C}$}

To explore whether further annealing can improve the level of $\mathrm{L} 1_{0}$ ordering in these films, as evidenced by the in-situ XRD study presented in section 3.1 , the samples annealed at $700^{\circ} \mathrm{C}$ were further annealed in the tube furnace at an increased temperature of $750^{\circ} \mathrm{C}$ for one hour. Figure 9 shows out-of-plane hysteresis loops for all the films in the matrix following the anneal step at $750^{\circ} \mathrm{C}$. The loops demonstrate a strong out-of-plane anisotropy where the squareness $(\mathrm{Mr} / \mathrm{Ms})$ of the loops is $\geq 90 \%$, which is consistent with a well textured $\mathrm{L} 1_{0}$ ordered phase. The "kinks" evident in the hysteresis data when the films were annealed at $700^{\circ} \mathrm{C}$ have been removed after further annealing at $750^{\circ} \mathrm{C}$, indicating that an annealing temperature of $700^{\circ} \mathrm{C}$ is not sufficient to fully order the samples. 


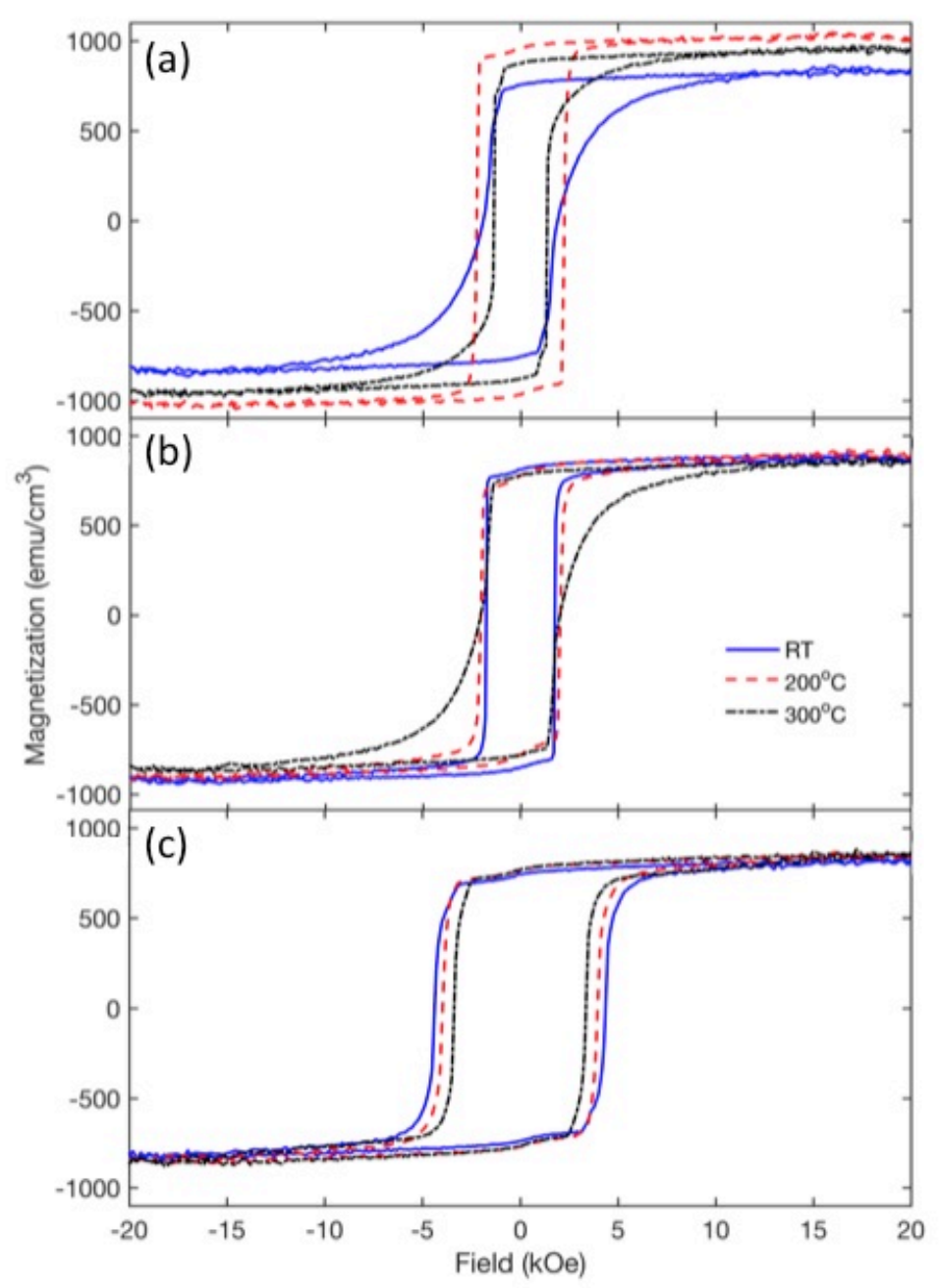

Figure 9. Perpendicular VSM measurements of the FePt thin films after annealing at $750^{\circ} \mathrm{C}$ for target DC bias voltages of (a) $200 \mathrm{~V}$, (b) $600 \mathrm{~V}$, and (c) $1000 \mathrm{~V}$, as a function of deposition temperature.

Values of coercivity, $\mathrm{H}_{\mathrm{c}}$, and estimated uniaxial anisotropy, $\mathrm{K}_{\mathrm{u}}$, for the annealed films are plotted in Figure 6 (c) and (d) respectively. Whilst the coercivity has been reduced after further annealing, the coercivity of the films deposited at a target DC bias voltage of $1000 \mathrm{~V}$ is still a factor of 2 greater than that of the other films. Comparing Figure $6(\mathrm{~b})\left(\mathrm{K}_{\mathrm{u}}\right.$ at $\left.700{ }^{\circ} \mathrm{C}\right)$ and Figure $6(\mathrm{~d})\left(\mathrm{K}_{\mathrm{u}}\right.$ at $\left.750{ }^{\circ} \mathrm{C}\right)$ there is little change in the anisotropy for these films, apart from a significant increase in $\mathrm{K}_{\mathrm{u}}$ for the sample deposited with a target DC bias voltage of $200 \mathrm{~V}$, at a substrate temperature of $200^{\circ} \mathrm{C}$. As the systematic differences observed in the coercivity for the $1000 \mathrm{~V}$ films are not reproduced in the anisotropy data, this strongly suggests that the mechanism responsible for higher reversal field in this series of samples results from the granular structure induced by the higher DC bias voltage and not improved ordering in the film. 


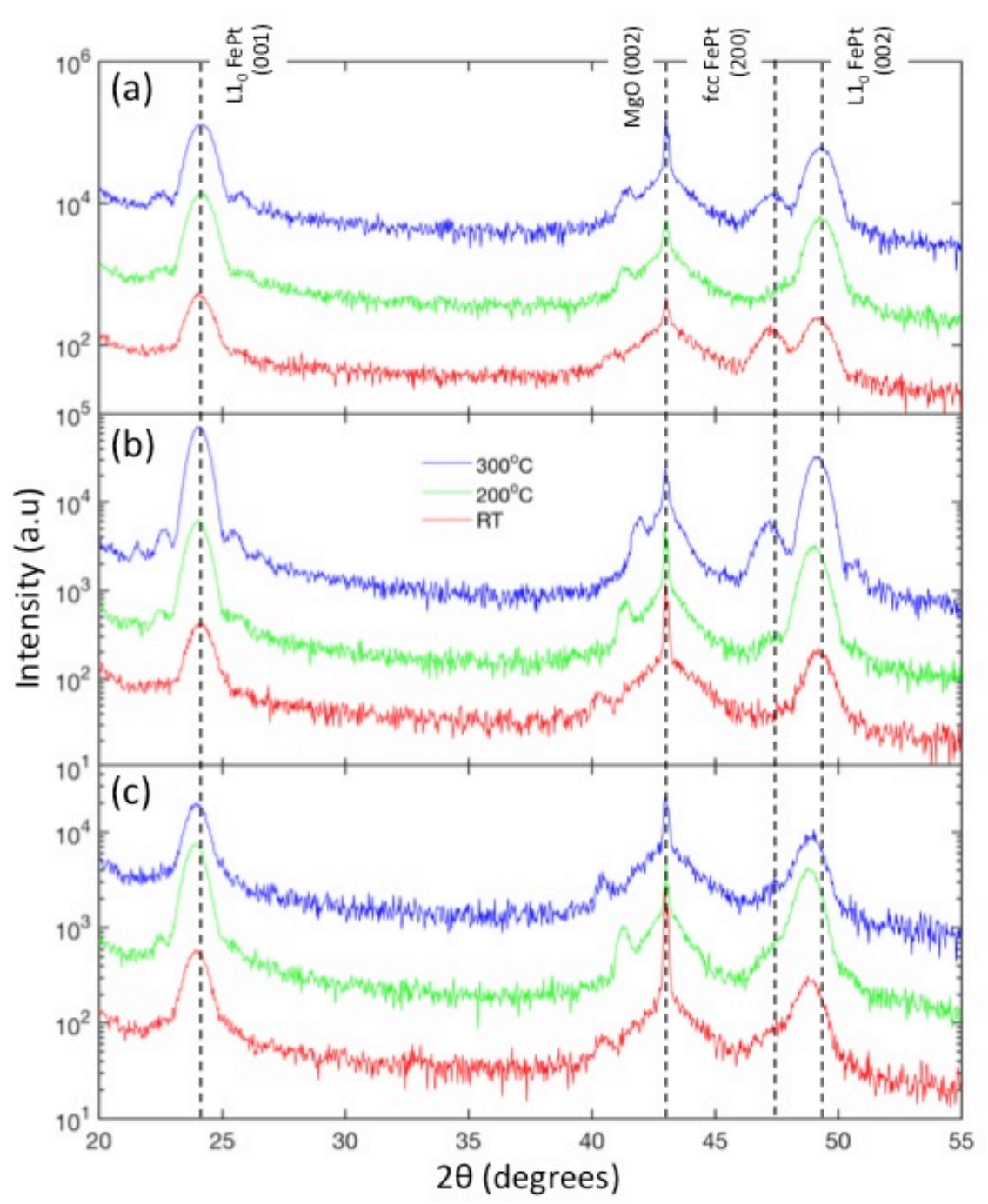

Figure 10. Perpendicular (out of plane) XRD data of the FePt thin films after annealing at $750^{\circ} \mathrm{C}$, deposited using a target DC bias voltage of (a) $200 \mathrm{~V}$, (b) $600 \mathrm{~V}$, and (c) $1000 \mathrm{~V}$, as a function of deposition temperature. The $2 \theta$ angles of the $\mathrm{MgO}(002)$, fcc $\mathrm{FePt}(200), \mathrm{L}_{0} \mathrm{FePt}(001)$ and (002) peaks are shown.

Figure 10 shows the XRD spectra for the matrix of films after annealing at $750{ }^{\circ} \mathrm{C}$ and confirms the presence of the $\mathrm{L} 1_{0}$ ordered phase in all the films through the presence of well developed (001) and (002) diffraction peaks. Comparing the XRD data in Figure 7 (annealed at $700^{\circ} \mathrm{C}$ ) with Figure 10 (annealed at $750^{\circ} \mathrm{C}$ ) there is a consistent trend for a reduction in the fcc FePt (200) peak. This is in agreement with the hysteresis data showing that the "kinks" observed for films annealed at $700^{\circ} \mathrm{C}$ were absent for films annealed at $750^{\circ} \mathrm{C}$. However, the change in XRD data with bias voltage is not identical for all films. In 
particular, the films deposited at 200V show the least change in XRD data whereas the films deposited at $600 \mathrm{~V}$ and $1000 \mathrm{~V}$ show greater changes with the sample deposited at $200^{\circ} \mathrm{C}$ showing the least (200) peak intensity following annealing at $750^{\circ} \mathrm{C}$.

These data confirm the initial in-situ XRD results demonstrating that the ordering process requires annealing temperatures in excess of $750^{\circ} \mathrm{C}$ to reach completion. The data also show that whilst it may be possible to "fine-tune" the ordering process by careful choice of deposition temperature and bias voltage, remote plasma sputtering does not offer a significant advantage towards creating thin films of $\mathrm{L} 1_{0}$ ordered FePt at lower deposition/anneal temperatures.

\section{Summary \& Conclusions}

In summary, we have explored the use of remote plasma sputtering to understand if this technique offers advantages over conventional DC magnetron sputtering for the direct fabrication of ordered $\mathrm{L} 1_{0} \mathrm{FePt}$ thin films with high perpendicular anisotropy. Initial studies focused on taking XRD measurements in-situ in order to observe the evolution of the $\mathrm{L}_{0}$ phase as the annealing temperature was increased. We observed that the ordered $\mathrm{L} 1_{0}$ phase occurred when the samples were annealed for temperatures in excess of $700^{\circ} \mathrm{C}$ and were fully ordered after annealing at $750^{\circ} \mathrm{C}$. In order to explore these results further we produced a number of FePt films that were deposited at a range of target DC bias voltages $(200 \mathrm{~V}, 600 \mathrm{~V}$ and $1000 \mathrm{~V})$ and substrate temperatures (room temperature, $200^{\circ} \mathrm{C}$, and $300^{\circ} \mathrm{C}$ ) in order to investigate how the deposition parameters affect the ordering, lattice parameters, and magnetic properties of the deposited films, which we determined using VSM and XRD.

The results show that the ordered $\mathrm{L} 1_{0}$ phase in FePt thin films cannot be induced using moderate (up to $\left.300^{\circ} \mathrm{C}\right)$ substrate temperatures during deposition. This was highlighted by the absence of any $\mathrm{FePt}(001)$ and (002) peaks and strong disordered (fcc) FePt (200) peaks in the as-deposited films. The L1 0 phase can only be induced when the films are post-annealed at temperatures in excess of $700^{\circ} \mathrm{C}$ as previously identified. Further, we have shown that the deposition temperature has no significant effect on the annealing temperature required to induce the ordered phase. Annealing films at a temperature of $750^{\circ} \mathrm{C}$ was shown to improve the level of ordering, resulting in well ordered films with strong perpendicular anisotropy. Optimal ordered films, with the highest $\mathrm{K}_{\mathrm{u}}$, are shown to be produced when deposited with a target DC bias voltage of $200 \mathrm{~V}$ and at a substrate deposition temperature of $200^{\circ} \mathrm{C}$, followed by post annealing for 1 hour at $750^{\circ} \mathrm{C}$. Depositing films at higher target DC bias voltages results in films with 
higher coercivities due which we ascribe to domain wall pinning at the boundaries between ordered and disordered states.

We conclude that whilst ordered $\mathrm{L} 1_{0}$ FePt thin films can be produced using remote plasma sputtering, high annealing temperatures are still required to induce the ordered phase. However, the use of remote plasma sputtering still offers other benefits, in particular uniform target utilization, which offers economic advantages over conventional approaches.

\section{Acknowledgements}

We gratefully acknowledge partial funding of this work under the EU Marie Curie programme FP7PEOPLE-2007-4-3-IRG “ANDIST”. 


\section{References}

[1] Weller D., Parker G., Mosendz O., Champion E., Stipe B., Wang X., Klemmer T., Ju G., Ajan A., “A HAMR Media Technology Roadmap to an Areal Density of 4 Tb/in ${ }^{20 "}$ IEEE Trans Mag, 50, 3100108 , 2014.

[2] Wood R., Williams M., Kavcic A., Miles J., "The Feasibility of Magnetic Recording at 10 Terabits Per Square Inch on Conventional Media” IEEE Trans Mag, 45, pp. 917-923, 2009.

[3] Yang J., Tan, C.P.H., Ong, E.H., “Thermal analysis of helium-filled enterprise disk drive” Microsyst Technol, 16, pp. 1699-1704, 2010.

[4] Kryder M.H., Gage E.C, McDaniel T.W., Challener W.A., Rottmayer R.E., Ju G., Hsia Y-T., Erden M.F. “Heat Assisted Magnetic Recording”, Proc IEEE, 96, pp. 1810-1835, 2008.

[5] Richter H.J. "The transition from longitudinal to perpendicular recording", J Phys D: Appl Phys, 40(9), R149, 2007.

[6] Weller D., Moser A., Folks L., Best M.E., Lee W., Toney M.F., Schwickert M., Thiele J.U., Doerner M.F., "High Ku materials approach to 100Gbits/in²", IEEE Trans Mag, 36, p. 10-15, 2002.

[7] Weller D., Moser A., “Thermal effect limits in ultrahigh-density magnetic recording”, IEEE Trans Magn, 35, pp. 4423-4439, 1999.

[8] Okamoto S., Kikuchi N., Kitakami O., Miyazaki T., Shimada Y., "Chemical-order-dependent magnetic anisotropy and exchange stiffness constant of FePt (001) epitaxial films", Phys Rev B, 66, $024412,2002$.

[9] Risyau R.A., Barmak K., Lewis L.H., Coffey K.R., Howard J.K., "On the relationship of high coercivity and $\mathrm{L} 1_{0}$ ordered phase in CoPt and FePt thin films", $J$ Appl Phys, 86, pp. 4527-4533, 1999.

[10] Toney M.F., Lee W-Y., Hedstrom J.A., and Kellock A., "Thickness and growth temperature dependence of structure and magnetism in FePt thin films", J Appl Phys, 93, pp. 9902-9907, 2003.

[11] Ju G., Peng Y., Chang E.K.C., Ding Y., Wu A.Q., Zhu X., Kubota Y., Klemmer T.J., Amini H., Gao L., Fan Z., Rausch T., Subedi P., Ma M., Kalarickal S., Rea C.J., Dimitrov D.V., Huang P-W., Wang K., Chen X., Peng C., Chen W., Dykes J.W., Seigler M.A., Gage E.C., Chantrell R., Thiele J-U., "High Density Heat-Assisted Magnetic Recording Media and Advanced Characterization-Progress and Challenges" IEEE Trans Mag, 51, 3201709, 2015. 
[12] Thwaites M.J., "High density plasmas” USA Patent No. 6463873, 15 Oct. 2002

[www.plasmaquest.co.uk]

[13] Vopsaroiu M., Thwaites M.J., Fernandez G.V. Lepadatu S. O’Grady K.,’Grain size effects in metallic thin films prepared using a new sputtering techniques", J Opto \& Adv Mater, 7, pp. 2713-2720, 2005.

[14] Vopsaroiu M., Georgieva M., Grundy P.J., Fernandez G.V, Manzoor S., Thwaites M.J., O’Grady K., "Preparation of high moment CoFe films with controlled grain size and coercivity", J Appl Phys, 97 , 10N303, 2005.

[15] Barton C.W., Slater T.J.A, Rowan-Robinson R.M., Haigh S.J., Atkinson D., Thomson T., "Precise Control of Inerface Anisotropy during Deposition of Co/Pd Multilayers" J Appl Phys, 116, 203903, 2014.

[16] Seki T., Shima T., Takanashi K., Takahashi Y., Matsubara E., Hono K., "L10 ordering of offstoichiometric FePt (001) thin films at reduced temperature”, Appl Phys Let, 82, pp. 2461-2463, 2003.

[17] Barmak K., Kim J., Lewis L.H., Coffey K.R., Toney M.F., Kellock A.J., \& Thiele J.U., "Stoichiometry-anisotropy connections in epitaxial L10 FePt (001) films", J Appl Phys, 95, pp. 7501$7503,2004$.

[18] Maeda T., Kai T., Kikitsu A., Nagase T., Akiyama J.I., "Reduction of ordering temperature of an FePt-ordered alloy by addition of Cu”, Appl Phys Lett, 80, pp. 2147-2149, 2002.

[19] Takahashi Y., Ohnuma M., Hono K., "Effect of $\mathrm{Cu}$ on the structure and magnetic properties of FePt sputtered film", J Magn Magn Mat, 246, pp. 259-265, 2002.

[20] Platt C., Wierman K., Svedberg E., Van de Veerdonk R., Howard J., Roy A., Laughlin D., "L-10 ordering and microstructure of FePt thin films with $\mathrm{Cu}, \mathrm{Ag}$, and Au additive", J Appl Phys, 92, pp. 6104$6109,2002$.

[21] Lee S.R., Yang S., Kim,Y.K., Na J.G., "Rapid ordering of Zr-doped FePt alloy films”, Appl Phys Let, 78, pp. 4001-4003, 2001.

[22] Chen J.S., Lim B.C., Ding Y.F, Chow G.M., "Low-temperature deposition of L1-0 FePt films for ultra-high density magnetic recording”, J. Magn Mag Mat, 303, pp. 309-317, 2006.

[23] Shima T., Moriguchi T., Mitani S., Takanashi K., "Low-temperature fabrication of L10 ordered FePt alloy by alternate monatomic layer deposition”, Appl Phys Let, 80, pp. 288-290, 2002. 
[24] Tran Y., Wright C.D., "Suppressed silicide formation in FePt thin films by nitrogen addition", $J$ Magn Mag Mat, 331, pp. 216-219, 2013.

[25] Berry, D. Barmak, K., "Time-temperature-transformation diagrams for the A1 to L10 phase transformation in FePt and FeCuPt thin films”, J Appl Phys, 101, 014905, 2007.

[26] Brombacher C., Schubert C., Neupert K., Kehr M., Donges J., Albrecht M., "Influence of annealing time on structural and magnetic properties of rapid thermally annealed FePt films", J Phys D: Appl Phys, 44, 355001, 2011.

[27] Weisheit M., Schultz L., and Fahler S., "Temperature dependence of FePt thin film growth on MgO(100)", Thin Solid Films, 515, pp. 3952 - 3955, 2007.

[28] Ho H., Laughlin D. E., Zhu J-G, “An X-Ray Diffraction-Based Method for Evaluating Inhomogeneous Ordering at the Grain Level of L1 $1_{0}$ - FePt Media”, IEEE Trans Mag, 48, pp. 2749-2752, 2012.

[29] Hu G., Thomson T., Rettner C., Raoux S., \& Terris B., "Magnetization reversal in Co/ Pd nanostructures and films”, $J$ Appl Phys, 97, 10J702, 2005.

[30] Thomson T., Lengsfield B., Do H., \& Terris B., "Magnetic anisotropy and reversal mechanisms in dual layer exchanged coupled perpendicular media", J Appl Phys, 103, 07F548, 2008.

[31] Waseda Y., Matsubara E., Shinoda K., X-ray diffraction crystallography: introduction, examples and solved problems, Springer Science \& Business Media, 2011.

[32] Pearson's Handbook of Crystallographic Data for Intermetallic Phases, American Society for Metals, Metals Park OH, 1985

[33] Futamoto M., Nakamura M., Ohtake M., Inaba N., Shimotsu T., "Growth of $\mathrm{L} 1_{0}$-ordered crystal in FePt and FePd thin films on $\mathrm{MgO}(001)$ substrate", AIP Advances, 6, 085302, 2016.

[34] Pisana S., Mosendz O., Parker G.J., Reiner J.W., Santos T.S., McCallum A.T., Richter H.J., Weller D., "Effects of grain microstructure on magnetic properties in FePtAg-C media for heat assisted magnetic recording”, J Appl Phys, 113, 043910, 2013.

[35] Thomson T, Hu G.,Terris B.D., "Intrinsic Distribution of Magnetic Anisotropy in Thin Films Probed by Patterned Nanostructures", Phys Rev Lett, 96, 257204, 2006. 